\title{
Winged-Cone Conformation in Hexa-p-tert-butylcalix[6]arene Driven by the Unusually Strong Guest Encapsulation
}

\author{
Felipe Terra Martins, ${ }^{*},+\notin \odot$ Breno Germano de Freitas Oliveira, ${ }^{,}$Ariel M. Sarotti, ${ }^{\S \odot}$ \\ and Ângelo de Fátima $*$ *ै॰ \\ ${ }^{\dagger}$ Instituto de Química, Universidade Federal de Goiás, P.O. Box 131, 74690-900 Goiânia, Brazil \\ ¥Grupo de Estudos em Química Orgânica e Biológica (GEQOB), Departamento de Química, Instituto de Ciências Exatas, \\ Universidade Federal de Minas Gerais, Av. Pres. Antônio Carlos 6627, 31270-901 Belo Horizonte, Brazil \\ ${ }^{\S}$ Instituto de Química Rosario (IQUIR), Universidad Nacional de Rosario-CONICET, Suipacha 531, S2002LRK Rosario, Argentina
}

\section{Supporting Information}

ABSTRACT: Hexa-p-tert-butylcalix[6]arene (1) is believed to adopt a winged conformation in a solution, featured by four phenyl rings perpendicular to the calix basis and two others at 1,4-positions lying down. However, there is some controversy on the occurrence of this conformation because it has never been found in the solid state of calix[6] arenes, regardless of the substitution pattern at lower and upper rims. Here, we have observed the winged-cone conformation for the first time in a solvate form of $\mathbf{1}$ with dimethyl sulfoxide (DMSO), dimethylformamide, and pyridine. The DMSO molecule is strongly encapsulated into 1 through two $\mathrm{OH} \cdots \mathrm{O}$ hydrogen
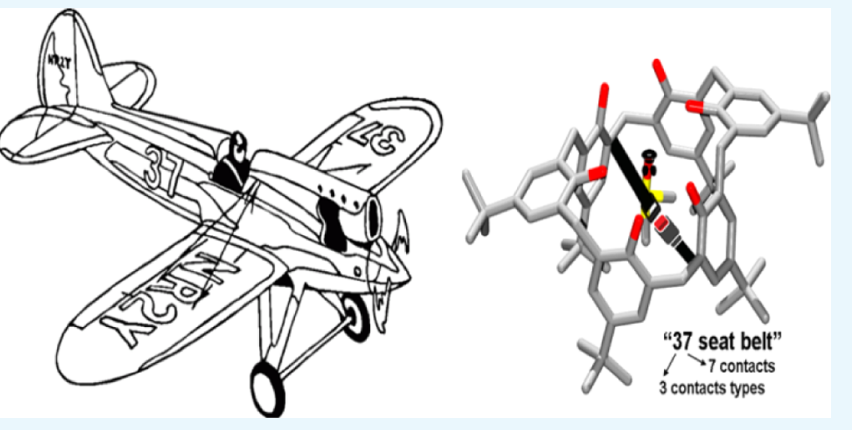
bonds with both flattened phenolic moieties, one $\operatorname{lp}_{(\mathrm{S})} \cdots \pi$ and four $\mathrm{CH} \cdots \pi$ interactions with the four perpendicular phenyl rings. This host-guest complex has energy lower by $23.4 \mathrm{kcal}^{\mathrm{mol}}{ }^{-1}$ than the isolated species. In addition, another DMSO solvate form with 1,2,3-alternate conformation was also obtained in this study, and its structure is compared with that of the precedent one. A detailed density functional theory study has also been carried out to understand the energetic relationships among cone conformers, intramolecular hydrogen-bonding patterns, and DMSO encapsulation.

\section{INTRODUCTION}

Calixarenes are macrocyclic compounds comprising phenolic units bonded to each other at 2,5-positions through methylene groups. ${ }^{1}$ The number of phenolic units can range according to synthetic conditions (e.g., reaction time and temperature) and catalyst (e.g., $\mathrm{NaOH}$ or $\mathrm{KOH}$ ), four, six, and eight units being the most common ones. ${ }^{2}$ Among them, the subset made up of four phenolic units, namely, calix[4]arenes, has been better investigated structurally than those composed with six (calix[6]arenes) and eight (calix[8]arenes) units. ${ }^{3}$ The conformations adopted by calix[4] arenes in both solution and solid states are well understood, as well as many solid-state structures are reported for them. ${ }^{4}$ To the best of our knowledge, there are 2866 entries in the CSD (version 5.38 with November 2016 update; 858655 entries) for general calix[4]arenes, whereas this number is 295 and 138 for the compounds with minimal framework of calix[6]arene and calix[8] arene, respectively.

The decorating of upper and lower rims means the recipe of getting new calixarenes for many desired properties, mainly for host-guest purposes. ${ }^{5}$ Before getting such planned compounds, the synthesis of hexa-p-tert-butylcalix $[n]$ arenes is the most widely used first step in the process due to its practical and rentable synthesis from $p$-tert-butylphenol, besides allowing easy control of the phenolic units number. ${ }^{6}$ Due to its leading role in the synthetic routes of most calixarenes, these compounds with p-tert-butyl groups at the upper rim are templates for the comprehension of structural and inclusion phenomena.

In this sense, compounds with six p-tert-butyl groups at the upper rim are the best investigated calix[6] arenes from the structural point of view. This can be viewed in its 185 known crystal structures (ca. $63 \%$ of all of calix[6] arenes entries in the CSD). Concerning the target compound of this study, hexa-ptert-butylcalix[6]arene (1), which is undecorated at the lower rim, has 13 crystal structures, a considerably large number if the few overall calix[6] arene structures in the CSD are taken into account. Interesting trends have been drawn from the available structural studies. For instance, it was found that 1 adopts a pinched cone conformation in the solid state when crystallizing with solvents that are not able to establish classical hydrogen bonds (hereinafter called as nonhydrogen-bonding solvents).

Received: June 30, 2017

Accepted: August 21, 2017

Published: August 31, 2017 
On the contrary, 1,2,3-alternate conformation is preferred in the presence of hydrogen-bonding solvents. ${ }^{8}$ Even though this calixarene has been well studied structurally, an old controversy remains. Molins et al. ${ }^{9}$ suggested in 1992 that $\mathbf{1}$ assumes a socalled winged conformation featured by four phenyl rings oriented perpendicularly to the molecule basis and two at 1,4positions being entirely flattened. However, their conclusion was based only on the NMR data in solution. No evidence for such a conformation in the solid state was available at the beginning of 1990s, thus providing an argument to Reinhoudt group $^{10}$ in 1996 to assign a pinched cone conformation as that existing in a solution. This conclusion was based on two main factors: the lower energy of the pinched cone and its occurrence in several crystal structures. In the course of the next two decades, other structures with pinched cone conformation have been reported for $\mathbf{1}$ in the solid state, ${ }^{11}$ but winged cone has not reported for any calix[6] arene thus far.

Here, we prepared a new multiple solvate form of $\mathbf{1}$ with dimethyl sulfoxide (DMSO), dimethylformamide (DMF), and pyridine. In this solvate, the winged-cone conformation was found for the first time in the solid state. It has one $C_{2}$ axis as the only molecular symmetry, as originally suggested by Molins et al. ${ }^{9}$ Furthermore, the whole DMSO molecule is strongly encapsulated into the winged cone through seven contacts (four $\mathrm{CH} \cdots \pi$, two $\mathrm{OH} \cdots \mathrm{O}$, and one lone pair $(\mathrm{lp})_{(\mathrm{S})} \cdots \pi$ ) with the six phenolic moieties. In addition to this unprecedented conformation in solid state, this solvate does not follow the trend of 1,2,3-alternate conformation when hydrogen-bonding solvents are cocrystallized, reinforcing the rarity of the structure reported here. We have also isolated another new solvate form of 1 , which is also presented here in full detail. This has only DMSO as the crystallization solvent and is the second finding of a DMSO solvate form of 1. Also, a detailed density functional theory (DFT) study was performed here, which helped us to understand the energetic relationships among conformations, intramolecular hydrogen-bond patterns, and DMSO encapsulation.

\section{RESULTS AND DISCUSSION}

2.1. Description of the Winged Cone. The multiple solvate of 1 with DMSO, DMF, and pyridine crystallizes with one molecule of each in the asymmetric unit (triclinic space group $\bar{P} 1$; Table $\mathrm{S} 1$ and Figure S1a). This crystal form means an important structural knowledge into calixarene chemistry in reason of two factors. First, we isolated for the first time in the solid state, the winged-cone conformation with a $C_{2}$ axis as the only symmetry element for a compound with the calix[6]arene basis (Figure 1b), regardless of the substitution pattern in the upper or lower rim. On the basis of low-temperature NMR spectral analysis, this conformation has been already suggested by Molins et al. ${ }^{9}$ in $\mathrm{CD}_{2} \mathrm{Cl}_{2}$ solution for the same calixarene studied here, the latter being questioned by Reinhoudt group ${ }^{10}$ due to the higher stability of the pinched cone conformation by $16.2 \mathrm{kcal} \mathrm{mol}^{-1}$ and the occurrence of the former in several solid-state structures. In turn, winged conformation has not been reported in the solid state up till now.

The winged-cone conformation can be described by an almost complete flattening of the 1,4-phenyl rings, labeled as A and $\mathrm{D}$, which, respectively, form the angles of 9.91(10) and 9.74(10) ${ }^{\circ}$, with the average molecular plane calculated through the four methylene carbons bonded at 2,5-positions of the two flattened phenyl rings. Just these four methylene carbons are coplanar, but all of the six ones point their hydrogens outward
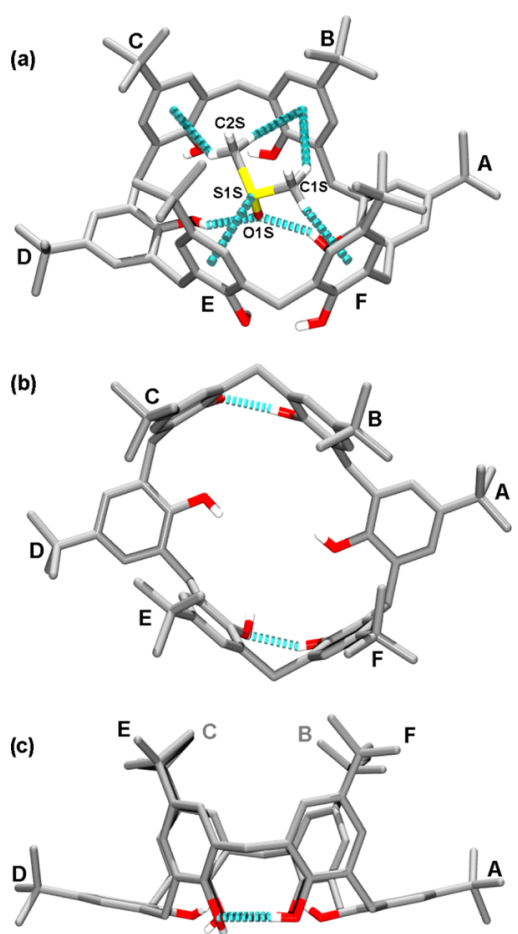

Figure 1. (a) Strong entrapping of DMSO in the multiple solvate of $\mathbf{1}$. (b) Top and (c) side views of the winged cone of $\mathbf{1}$ found in this solvate. In all of the panels, $\mathrm{CH}$ hydrogens of 1 were omitted and phenolic labeling scheme is shown.

the cone, as believed previously, whereas two methylene groups point inward the pinched cone. The capital letters from A to $\mathrm{F}$ were used to label the phenolic moieties in both structures reported here (Figure S1), and they have been employed to refer to both phenyl rings and their oxygens throughout the text and drawings. The other four aromatic rings are almost perpendicular, forming the angles of $77.46(9)^{\circ}(\mathrm{B}), 86.72(11)^{\circ}$ (C), 82.44(10) ${ }^{\circ}(\mathrm{E})$, and $84.99(10)^{\circ}(\mathrm{F})$, with the mean molecular plane just defined. All of the six methylene groups are pointed outward the winged cone.

A similar winged conformation has been found in a coordination complex in which all of the $\mathrm{OH}$ groups undergo deprotonation and all of the resulting phenolate oxygens are coordinated to iron ions entrapped in the minor cavity. ${ }^{12}$ Furthermore, the four phenolate oxygens belonging to the perpendicular aromatic rings are further coordinated to potassium ions. However, the occurrence of such a conformation in this structure cannot be extrapolated to free calix[6]arenes because electrostatic and coordination bonds dramatically change the conformational equilibrium. Even so, a $C_{2 v}$ molecular symmetry without a cone distortion is observed in such calix[6]arene, differing therefore from that found in this study.

2.2. DFT Calculations on Pinched, 1,2,3-Alternate and Winged-Cone Conformers. To get energetic insights into the conformational preference of 1 , we undertook DFT calculations at the B3LYP/6-31G* level of theory. To explore the most stable cone conformations, several rotamers were generated by exhaustive modifications of the dihedral angles of all of the $\mathrm{OH}$ groups starting from the crystal structures of the winged cone and 1,2,3-alternate structures determined in this study, and the pinched cone one from a literature crystal structure (CSD reference code TECDUB). ${ }^{11 \mathrm{~b}}$ The $\mathrm{C}-\mathrm{H}$ 
coordinates of all of the rotamers were partially optimized at the $\mathrm{B} 3 \mathrm{LYP} / 6-31 \mathrm{G}^{*}$ level of theory while freezing the internal coordinates of all of heavy atoms, and the lowest energy conformation found in each case was next fully optimized without constrains at the same theory level. The coordinates of all of the optimized rotamers can be found in the Supporting Information.

The fully optimized structure of the winged-cone conformer yielded an idealized $C_{2}$ symmetry molecule with two perpendicular phenyl rings with twists of 69.36 and $84.55^{\circ}$ and just one flattened ring with a bent of $2.14^{\circ}$. It is less stable by $15.9 \mathrm{kcal} \mathrm{mol}^{-1}$ than the lowest energy pinched cone conformer, which is the most stable one among all of the evaluated conformers due to its six intramolecular hydrogen bonds. This theoretical pinched cone conformer does not differ significantly from that used as the starting geometry. ${ }^{11 \mathrm{~b}}$ Such an energy difference is in agreement with that found by Reinhoudt group $\left(16.2 \mathrm{kcal} \mathrm{mol}^{-1}\right) .{ }^{10}$ Interestingly, according to our calculations, the winged cone is the highest energy conformation in the gas phase because the 1,2,3-alternate conformation is less stable than the pinched cone by 11.8 $\mathrm{kcal} \mathrm{mol}^{-1}$. Such a stability order, namely, pinched cone $>1,2,3-$ alternate $>$ winged cone, was also found in another DFT approach for $1 .{ }^{13}$ However, in that study, only the input of the pinched cone conformation came from a solid-state structure.

2.3. Hydrogen Bonds in Winged-Cone Conformers: Description and DFT Calculations. The loss of the mirror symmetry in the winged-cone conformer was attributed to the clockwise (CW) or counterclockwise (CCW) sense of six cyclic intramolecular hydrogen bonds. ${ }^{9}$ However, our structure shows that the formation of a $C_{2}$ winged cone is not dependent of such an intramolecular hydrogen-bonding array. The asymmetric cone distortion and the consequent mirror symmetry loss occur with only two intramolecular $\mathrm{OH}$... $\mathrm{O}$ interactions, and neither CW nor CCW sense is found. Only two intramolecular hydrogen bonds are formed between the perpendicular phenol moieties (Figure $1 \mathrm{~b}$ ), whereas the other four $\mathrm{OH}$ groups are intermolecular hydrogen-bonding donors to solvent molecules (Figures $1 \mathrm{a}$ and $2 \mathrm{~b}$, Table S2 for contacts metrics). Two perpendicular $\mathrm{OH}$ groups are hydrogen-bonding donors to DMF and pyridine, which are located outside the calixarene cone (Figure 2). The two $\mathrm{OH}$ moieties of the wings are hydrogen-bonding donors to oxygen from DMSO (Figure 1a), which is entirely entrapped into the cone.

However, the lowest-energy winged-cone conformer is present with either CW or CCW sense of four noncyclic intramolecular hydrogen bonds, wherein the $\mathrm{OH}$ groups from both flattened rings act only as acceptors. This conformer is labeled as W1 and can be viewed in Figure 3a together with other conformers having energy up to $10 \mathrm{kcal} \mathrm{mol}^{-1}$ above that of W1. For all of them, two mirror conformers have the same energy and can be converted into each other by simultaneously changing the sense of all of the $\mathrm{OH}$ hydrogen positions and distorting the cone toward the other side. This can be clearly noted in Figure 3a, where the two possible W1 conformers with either CW or CCW sense of four noncyclic intramolecular hydrogen bonds are shown. If just one of the two flattened phenolic moieties acts as a hydrogen-bonding donor, there is an increase of $0.5 \mathrm{kcal} \mathrm{mol}^{-1}$ in the energy in the second-ranked gas-phase conformation (conformer W2). In this case, such $\mathrm{CW}$ and $\mathrm{CCW}$ senses are lost, but the four intramolecular $\mathrm{OH} \cdots \mathrm{O}$ bonds are still kept. However, if either CW or CCW sense of the four hydrogen bonds is featured with both (a)

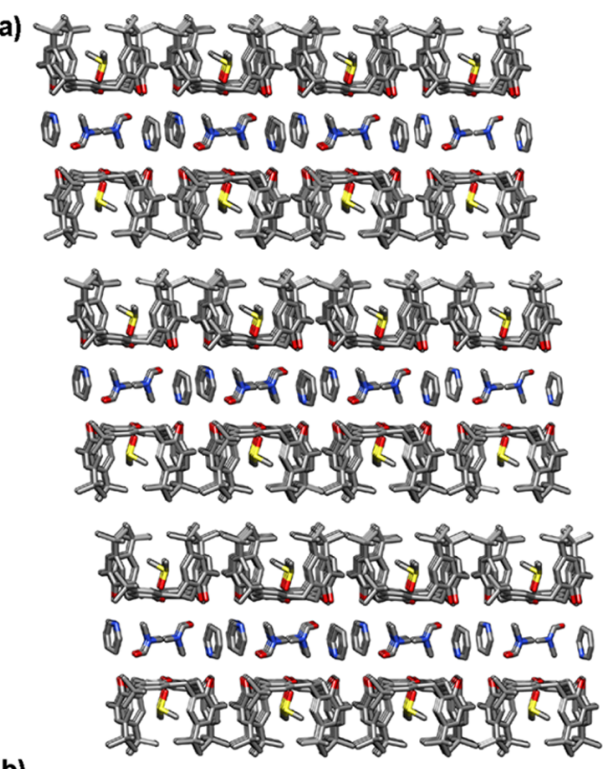

(b)

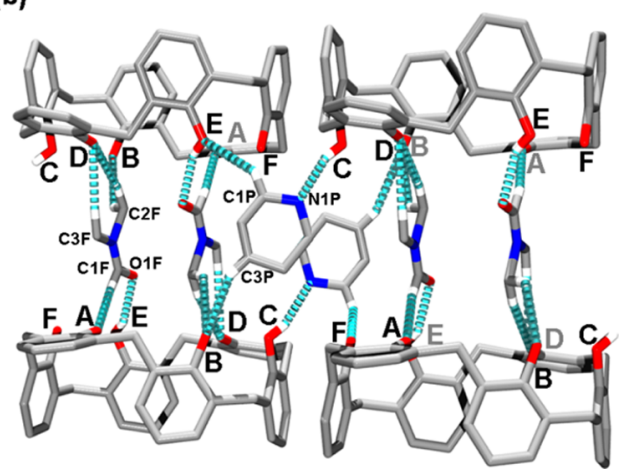

Figure 2. (a) Overview of the crystal packing in the multiple solvate of 1. All of the hydrogens are hidden in this picture. (b) Hydrogen bonds (cyan dashed lines) involving DMF, Pyr, and 1. Only hydrogens participating in the shown interactions are not hidden in this drawing, where $t$-butyl groups are also omitted. Labeling scheme is shown for phenolic groups and nonhydrogen solvent atoms acting as hydrogenbonding donor or acceptor.

flattened phenolic groups being donors, which is the same of changing the hydrogen bonds sense without distorting the cone, the energy is higher by $3.2 \mathrm{kcal} \mathrm{mol}^{-1}$ (conformer W5) than that of the lowest-energy conformer. Similarly, a higherenergy conformer, destabilized by $7.6 \mathrm{kcal} \mathrm{mol}^{-1}$ relative to the lowest-energy conformer, is observed if the hydrogen bonds sense of the second-ranked conformer is changed without cone distortion (conformer W6 in Figure 3a). Just one winged-cone conformer with two intramolecular hydrogen bonds (conformer W8 in Figure 3a) has energy within the $10 \mathrm{kcal} \mathrm{mol}^{-1}$ range above the most stable one. If only the four perpendicular phenolic groups of this last conformer are considered, there is a $\mathrm{CW}$ or CCW sense of $\mathrm{OH}$ hydrogen orientation, which does not occur in the crystal geometry (Figure 1b).

2.4. DMSO Encapsulation into Winged-Cone and Crystal Packing. The winged-cone conformer found in the multiple solvate has energy $10 \mathrm{kcal} \mathrm{mol}^{-1}$ above that of the most stable winged-cone conformer, which should be compensated intermolecularly. Also, there is a need to overcome the $15.9 \mathrm{kcal} \mathrm{mol}^{-1}$ difference relative to the lowest-energy pinched cone conformer. Even so, just the DMSO encapsulation energy appears to be almost enough to 
(a)
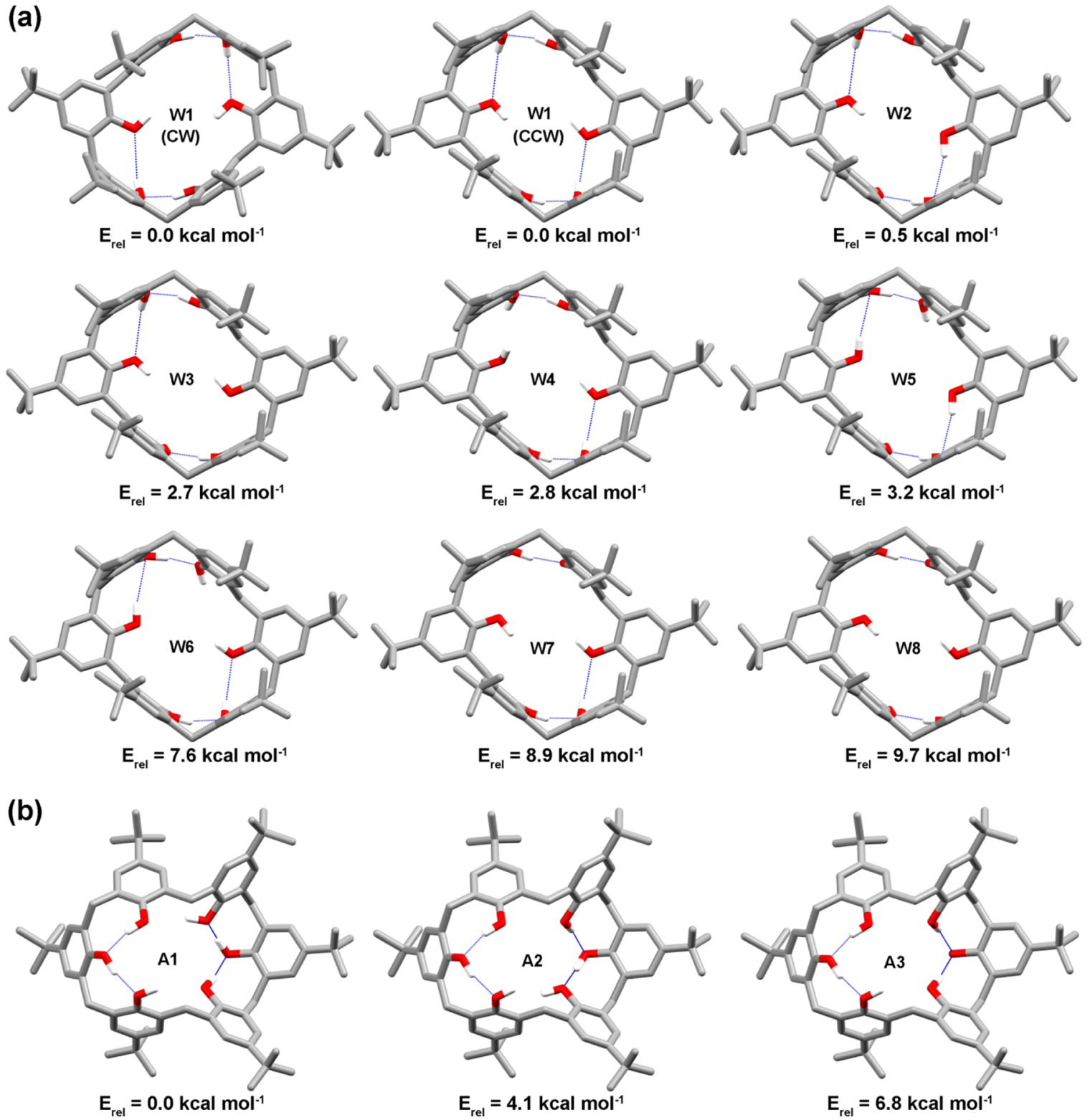

Figure 3. (a) Winged-cone and (b) 1,2,3-alternate conformations of 1, optimized at B3LYP/6-31G* level of theory, whose energy is up to 10 kcal $\mathrm{mol}^{-1}$ above the most stable conformer $\left(E_{\mathrm{rel}}=0.0 \mathrm{kcal} \mathrm{mol}^{-1}\right)$. Crystal geometries determined in this study are used as an input and only hydrogens were not constrained in the calculations. Conformer labeling is also shown. All of the shown conformers have two mirror images of identical energies, as illustrated only for W1.

allow this unfavorable conformation. The DFT-optimized host-guest complex between $\mathbf{1}$ and DMSO, also starting from the crystal coordinates, has the energy lower by $23.4 \mathrm{kcal}$ $\mathrm{mol}^{-1}$ than the sum of the energies of the isolated species optimized at the same level of theory. This encapsulation energy is high and demonstrates how the strength of DMSO is entrapped into the winged cone. In fact, DMSO molecule is strongly held into the calixarene cavity by using intermolecularly its whole molecule. There are seven contacts of three types between DMSO and 1. Besides accepting the two classical hydrogen bonds from the two flattened $\mathrm{OH}$ groups, its two methyl moieties are involved in four $\mathrm{CH} \cdots \pi$ interactions. Likewise, one $\operatorname{lp}_{(s)} \cdots \pi$ interaction between sulfur atom and the aromatic $\pi$-system occurs too. The latter interaction is even responsible for the disorder found in the DMSO molecule. Its sulfur atom stays in two sites of 70 and $30 \%$ occupancy each, whereas its methyl carbon and oxygen, however, have occupied just one $100 \%$ occupancy site, common to both positions. Consequently, in one position (70\% occupancy), sulfur atom interacts with ring E, and, in another one (30\% occupancy), it is interacting with ring $\mathrm{B}$. The major and minor occupancy sulfur sites are distanced by $3.336(2)$ and $3.372(5) \AA$ from the centroids calculated through carbons of rings $\mathrm{E}$ and $\mathrm{B}$, respectively. In fact, $\operatorname{lp}_{(\mathrm{S})} \cdots \pi$ interactions are known as noncovalent contacts stabilizing the solid-state structures of small molecules ${ }^{14}$ and also the folding of biomolecules. ${ }^{15}$ Here, it helps in strongly holding a guest into its host.

The second worthy structural finding of this multiple solvate resides in the observation of a cone conformation together with the hydrogen-bonding solvents, contrary to the tendency that such a conformation is adopted only in the presence of nonhydrogen-bonding solvents. Hydrogen-bonding solvents (DMSO, acetone, dioxane/water, DMF) have induced 1,2,3alternate conformation, ${ }^{8}$ whereas the pinched cone conforma- 
(a)

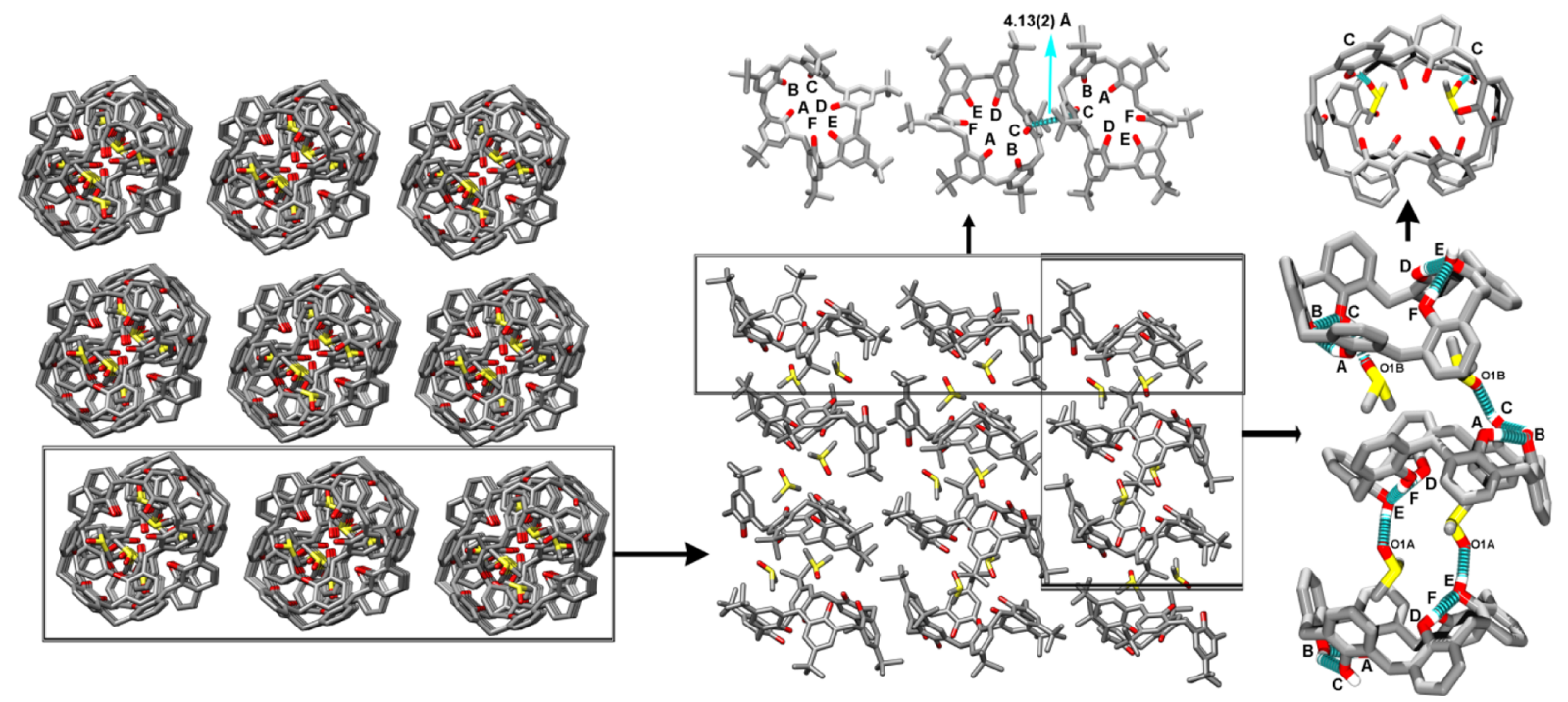

(b)
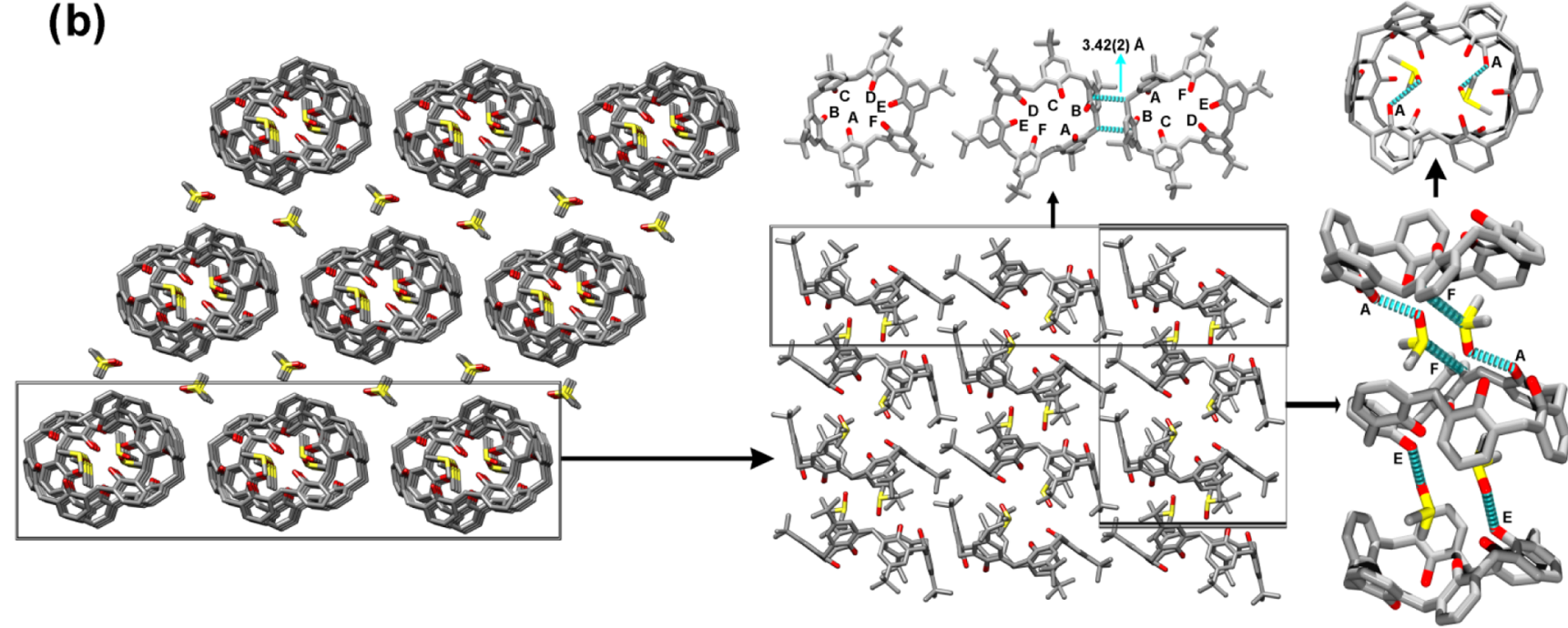

Figure 4. Comparison of the main crystal packing features found in the DMSO solvates of $\mathbf{1}$ in (a) our study and (b) the literature. In the left panels, a top view of the columns is displayed, detaching the formation of voids and solvate channels in (a) and (b), respectively. In the middle panels, a front view of the three columns made up of four calixarene molecules each is shown. A top inset is detached to show the calixarene rotation around the column axis and the different weak contact patterns in (a) and (b). In the right panels, the intramolecular and intermolecular hydrogen bonds are detailed as cyan dashed lines. A top inset is devoted to show the different DMSO binding sites to the side hydroxyl group in the two solvate forms. In (a), only the hydrogens participating in the shown interactions are not hidden in the right panel. The $t$-butyl groups were not omitted only in the middle panels in (a) and (b). Alone capital letters refer to the labeling scheme of the phenolic groups. DMSO oxygens were also labeled in the right panel in (a).

tion is related to the crystallization of nonhydrogen-bonding solvents (benzene, chloroform, acetonitrile, carbon disulfide, tetrachloroethylene, toluene, dichloromethane, bromobenzene, and chlorobenzene). ${ }^{11}$ Therefore, our structure is an exception to this series. At last, the overall packing of the multiple solvate is featured by the formation of layers of host-guest complexes, which are face-to-face packed on top of each other (Figure 2a). Their tail-to-tail packing does not occur due to the intercalation of a solvent layer made up of pyridine and DMF molecules (Figure 2a). These two solvents act as cross-links between the lower rims of calixarene molecules on the adjacent layers through the aforementioned classical hydrogen bonds and several further nonclassical $\mathrm{CH}_{\mathrm{pyr} / \mathrm{DMF}} \cdots \mathrm{O}_{\text {calix }}$ ones, as shown in Figure $2 b$.

2.5. DMSO Solvate. Here, we have also isolated another new solvate of 1 . Its structure was solved in the monoclinic space group $C 2 / c$ with one calixarene and two DMSO molecules in the asymmetric unit (Table S1 and Figure S1b). This is the second report of a DMSO solvate of $\mathbf{1}$ because there is a literature precedent with two and half DMSO molecules and one calixarene in the asymmetric unit of a triclinic unit cell $(\bar{P} 1$ space group $){ }^{8}$ In that structure, two full occupancy solvent molecules correspond to those found in our structure (see below their similar entrapping patterns), whereas one fractional DMSO molecule of $50 \%$ occupancy was also found there. It is important to state that we have identified a smeared electron density in the difference Fourier map when refining our DMSO solvate structure. However, it was not possible to assign it to any fractional DMSO molecule. Therefore, the data were squeezed with Platon in the latter stages of refinement, which was also applied to the crystal data from the multiple solvate previously described. 
In our DMSO solvate, however, it is possible to have a solvent fraction in the remaining void of $402.5 \AA^{3}$ solvent accessible volume per unit cell. This hypothesis is reinforced if the formation of channels where the voids and nonintegral DMSO molecules are in our and in the known DMSO solvate, respectively (Figure 4), is taken into account. Here, however, we will refer to our structure only as a solvate without ascertaining the solvent stoichiometry because neither the presence nor the amount of DMSO in the channel was concluded. In fact, the crystals obtained in this study from a DMSO solution had diffracted poorly even at a mediumresolution shell, precluding the assignment of low electron density such as that from a fractional or disordered solvent molecule. Even so, the found void has a volume compatible to that of four DMSO molecules (molecular volume of 105.5 $\left.\AA^{3}\right),{ }^{16}$ inferring, therefore, the presence of half of one disordered DMSO in the asymmetric unit of our solvate crystallized in the $C 2 / c$ space group. This would totalize two and half DMSO molecules in our solvate, as also occurred in the literature.

2.6. Conformation and Intramolecular Hydrogen Bonds in the DMSO Solvate: Description and DFT Calculations. Calixarene conformations are resembled in both DMSO solvates (Figure 5) and follow the 1,2,3-alternate

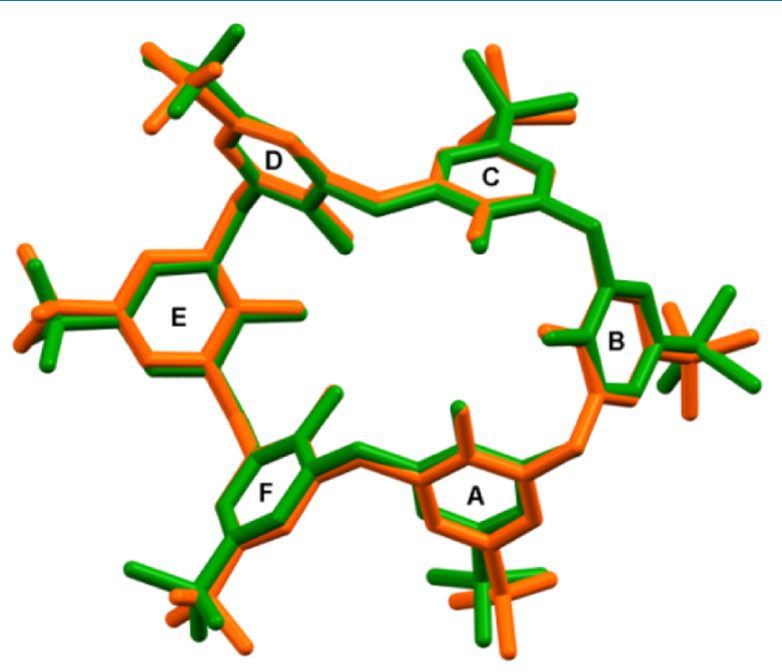

Figure 5. Superposition of $\mathbf{1}$ in their crystal conformation found in the DMSO solvates in our (green) study and in the literature (orange).

conformation trend when isolated out from hydrogen-bonding solvents. In both structures, there is the formation of two alternate cones made up of the trimeric subunits $A B C$ and DEF. Each trimeric subunit has one middle (B or E) and two side ( $\mathrm{A}$ and $\mathrm{C}$ or $\mathrm{D}$ and $\mathrm{F}$ ) phenolic moieties. However, these two halves are not similar. Compared with $\mathrm{D}, \mathrm{E}$, and $\mathrm{F}$, the three phenyl rings $\mathrm{A}, \mathrm{B}$, and $\mathrm{C}$ are more perpendicular to the average molecular plane passing through the four methylene carbons bonded to the two middle phenyl rings. In our solvate, the least-square plane calculated through the phenyl rings from the first subunit forms the angles of $48.91(15)^{\circ}(\mathrm{A}), 83.69(14)^{\circ}$ (B), and $64.94(18)^{\circ}(\mathrm{C})$, with the mean molecular plane as defined before, whereas these values for the phenyl rings in the another trimeric subunit are $46.94(13)^{\circ}(\mathrm{D}), 44.01(14)^{\circ}(\mathrm{E})$, and $44.16(13)^{\circ}(\mathrm{F})$. In the literature DMSO solvate, the corresponding measurements are $46.4(2)^{\circ}(\mathrm{A}), 83.9(3)^{\circ}$ (B), 66.6(3) ${ }^{\circ}(\mathrm{C}), 54.5(2)^{\circ}(\mathrm{D}), 43.6(3)^{\circ}(\mathrm{E})$, and $34.3(3)^{\circ}(\mathrm{F})$.
On the basis of these bent values, it is possible to observe that the phenyl rings $\mathrm{E}$ and $\mathrm{F}$ are less inclined than those of all of the others in both DMSO solvates, even though their bent is more resembled in our solvate than in the previous one. Full optimization of the lowest-energy conformer starting from our $1,2,3$,-alternate conformer also revealed the presence of two different subunits, with equivalent angles between the phenyl rings $\mathrm{A}-\mathrm{F}$ and the average calyx base of $48.62,86.75,54.92$, 56.05, 29.53, and $45.99^{\circ}$.

The intramolecular pattern of the hydrogen bonds is also conserved in the solvates, with two interactions per subunit. In the subunit $A B C$, hydroxyl group on one side is not an intramolecular hydrogen-bonding donor, whereas in the DEF one, the middle hydroxyl moiety does not donate a intramolecular hydrogen bonding (Figure 4, right panels; Table S3 for contacts metrics). These two $\mathrm{OH}$ groups are hydrogen-bonding donors to DMSO oxygens instead (see below). To the best of our knowledge, hydrogens have been not positioned in the antecedent structure. Therefore, this is the first report of an accurate hydrogen-bonding geometry in the solvates of $\mathbf{1}$ with hydrogen-bonding solvents. Such different intramolecular hydrogen-bonding sets between the subunits is a consequence of the interactions with DMSO because the 1,2,3-alternate conformation found in the DMSO solvates is only the third ranked gas-phase conformation (conformer A3 in Figure 3b). It has a higher energy of $6.8 \mathrm{kcal}$ $\mathrm{mol}^{-1}$ relative to the most stable conformer, which is again featured by either CW or CCW sense of four intramolecular noncyclic hydrogen bonds. In this conformation, the absence of these senses is responsible for an energy increase of $4.1 \mathrm{kcal}$ $\mathrm{mol}^{-1}$ (conformer A2 in Figure $3 \mathrm{~b}$ ).

2.7. Crystal Packing in the DMSO Solvate. Both DMSO solvates are featured by the presence of columns comprised of calixarene molecules intercalated by two entrapped DMSO molecules (Figure 4). Consequently, each half of the alternate double cone lies on the top of another one. In this layout, the hydroxyl groups of one trimeric subunit are packed close to the $t$-butyl moieties of another unit, that is, phenolic units A, B, and $\mathrm{C}$ are face-to-tail packed on those units labeled as D, E, and F, respectively. The first difference between the two solvates rises from the rotation of calixarenes around the column axis. If the literature DMSO solvate is taken as the reference, ${ }^{8}$ the calixarene molecules are rotated by ca. $60^{\circ}$ around the column axis in our solvate. This can be observed in the side-to-side packing fashion of the columns (Figure 4, middle-top panels). In the literature solvate, the middle phenolic units of calixarene molecules on the neighboring columns are packed together through $\mathrm{CH}_{\text {methylene }} \cdots \pi$ contacts. On the other hand, in our solvate, side phenolic units $\mathrm{C}$ are closer than the middle ones due to a weak $\pi \cdots \pi$ interaction between them (Figure 4, middle-top panels). No $\mathrm{CH} \cdots \pi$ contact occurs when pillaring such columns in the DMSO solvate reported here.

The difference between the two DMSO solvate forms does not stop here. Even though a similar pattern of classical $\mathrm{OH}_{\text {calix }} \cdots \mathrm{O}_{\text {DMSO }}$ hydrogen bonds is kept in both structures, with one crystallographically independent DMSO molecule hydrogen bonded to the middle phenolic $\mathrm{OH}$ group and another one to a side hydroxyl moiety (Figure 4, right panels), there is a notable difference in the DMSO interaction site in the calixarene molecules. In the known solvate, each two solvent molecules interacting with the side hydroxyl groups from the neighboring calixarenes packed into the column are related by an inversion symmetry, that is, hydrogen-bonding $\mathrm{OH}$ donor 
moieties lie on the opposite sides of the plane crossing through the 1,4-carbons from the middle aromatic rings. In our structure, contrarily, these two $\mathrm{OH}$ donor groups are related by a twofold rotation axis and are on the same side of the plane aforementioned. These different sites of DMSO binding to the side hydroxyl group can be viewed in Figure 4, at the right top panels. Consequently, the orientation of DMSO molecules hydrogen bonded to the side hydroxyl group into the cones changes a few in the solvates, which can be seen by the presence of $\operatorname{lp}_{(\mathrm{s})} \cdots \pi($ ring $\mathrm{F}$ ) interaction only in the literature solvate. The pattern of $\mathrm{CH} \cdots \pi$ contacts is consequently affected, but comparison between the two structures is not accurate because hydrogens were not positioned in the solvate form elucidated in 1996.

\section{CONCLUSIONS}

In summary, for the first time, winged cone is reported in the solid state for calix[6]arene. The structural features derived from this study match with those suggested in 1992 by Molins et al. in a solution, except for the cyclic intramolecular hydrogen-bonding motif. In fact, the asymmetric cone distortion occurs with only two intramolecular $\mathrm{OH} \cdots \mathrm{O}$ interactions and neither CW nor CCW sense is found, even though our theoretical approaches indicate that an energy lowering could occur if these senses are adopted. A higher energy in solid state is supported by the energy compensation from the strong DMSO encapsulation, besides other intermolecular interactions with DMF and pyridine. This structural exception having three hydrogen-bonding solvents disagreed with the general conformational trend of calix[6]arenes in solvatomorphs, highlighting the complexity of the balance between packing and intramolecular driving forces. However, although this multiple solvate reveals that this trend cannot be a rule, the second DMSO solvate form adopting 1,2,3-alternate conformation reinforces its use as a good approach for the relationship between calix[6] arene conformation and solvent ability to realize a classical hydrogen bond. The intriguing DMSO locking into the winged cone is also another important finding, which will be useful to guide the encapsulation of DMSO-like molecules into calix[6]arenes.

\section{EXPERIMENTAL SECTION}

4.1. Synthesis and Crystals Preparation. Compound 1 was synthesized according to the known protocol. ${ }^{6,17}$ Next, compound 1 was dissolved in very binary and ternary solvent combinations and then allowed to stand at $25{ }^{\circ} \mathrm{C}$ in the dark. The two successful combinations yielding the new crystal forms described in this study will be detailed in sequence. A calixarene mass was weighed $(5 \mathrm{mg})$ and dissolved at room temperature in either a mixture of DMSO $(2 \mathrm{~mL})$ and DMF $(2 \mathrm{~mL})$ or a mixture of DMSO $(1 \mathrm{~mL}), \mathrm{DMF}(1 \mathrm{~mL})$, and pyridine $(1 \mathrm{~mL})$. After the dissolution step, the glass crystallizers were not sealed and then kept upon standing for 15-20 days. Before complete solvent evaporation, the crystals of the new DMSO solvate or the DMSO/DMF/Pyr solvate of $\mathbf{1}$ were isolated out from the two solvent systems, respectively, before collecting the singlecrystal X-ray diffraction data.

4.2. Structure Determination. Suitably shaped single crystals of the multiple and DMSO solvate forms were selected for the X-ray diffraction data measurement on a Bruker-AXS Kappa Duo diffractometer with an APEX II CCD detector. Mo $\mathrm{K} \alpha$ radiation from an $\mathrm{I} \mu \mathrm{S}$ microsource with multilayer optics was used as the incident X-ray beam. The diffraction images were recorded by $\varphi$ and $\omega$ scans set using APEX2 software, $^{18}$ which was also employed to deal with the raw data sets (indexing, integrating, reducing, and scaling of the Bragg reflections). Next, the following crystallographic software were used: SIR2004 ${ }^{19}$ (structure solving), SHELXL-97 $7^{20}$ (structure refinement), MERCURY, ${ }^{21}$ and ORTEP- ${ }^{22}$ (structure analysis and representations). The asymmetric units were solved through the assignment of all of the nonhydrogen atoms directly from the Fourier synthesis of electron density. The electron density map was constructed by inputting the structure factors whose phases were first retrieved using the direct methods. After structure solving, the models were refined by full-matrix least-squares method on $F^{2}$, with free anisotropic and constrained isotropic atomic displacement parameters for nonhydrogen and hydrogen atoms, respectively. The $U_{\text {iso }}$ values of hydrogens were set to $1.2 U_{\text {eq }}$ of the bonded carbon, except for methyl hydrogens in which their $U_{\text {iso }}$ was set to $1.5 U_{\text {eq }}$ of the parent carbon. The hydroxyl hydrogens had also their $U_{\text {iso }}$ constrained to $1.5 U_{\text {eq }}(\mathrm{O})$. All of the hydrogen positions were stereochemically defined and constrained in the refinements, keeping idealized geometry regardless of the changes in the positions of the bonded atoms. However, all of the $\mathrm{OH}$ hydrogens were first identified from the difference Fourier maps and checked for suitable intra- and intermolecular hydrogen-bonding geometries before their constraining.

The positional disorder was possible to be refined for some $t$ butyl moieties of both solvates using the classical split-atom approach. Two atomic sites sets of equal occupancy were found for each $t$-butyl fraction and then their occupancy was constrained during refinements. The labels of a disordered site set differed from another corresponding one by a terminal apostrophe. In the multiple solvate form, sulfur atom of the DMSO molecule was also disordered over two sites of constrained 70 and $30 \%$ occupancy factors.

It is important to mention that both crystals were extremely thin plates diffracting X-rays poorly even at a mediumresolution shell. Furthermore, they have loosened solvent molecules when away from the crystallization system, undergoing even decrease of the long-range order (only $26 \%$ of the observed reflections for the best X-ray diffraction data set collected to the new DMSO solvate). In both structures, diffuse electronic density, identified as low electron density peaks, was found in the difference Fourier map, which can be from nonstoichiometric loosing solvent molecules. However, even after several trial refinements attempting to assign these low electron density peaks to low occupancy atom sites, the identification of any solvent was not possible and the data were squeezed using Platon ${ }^{23}$ before ending the refinement.

4.3. Theoretical Calculations. All of the calculations were performed using Gaussian 09. ${ }^{24}$ The geometries of the single molecules were extracted from the crystal structures, and several conformations were generated by exhaustive modifications of the dihedral angles of all of the $\mathrm{OH}$ groups. The $\mathrm{C}-\mathrm{H}$ coordinates of all of the rotamers were partially optimized at the B3LYP/6-31G* level of theory ${ }^{25}$ while freezing the internal coordinates of all of the heavy atoms. In addition, the geometries were fully reoptimized without constraints at the HF/3-21G level of theory, and normal coordinate analyses were used to confirm the nature of the stationary points. The most stable geometries found at the HF/3-21G level were further reoptimized without constrains at the B3LYP/6-31G* level of theory. To estimate the binding energy of the 1-DMSO 
host-guest complex, the geometries of the complex and of the individual species were extracted from the crystal structure, and the $\mathrm{C}-\mathrm{H}$ and $\mathrm{O}-\mathrm{H}$ coordinates were optimized at the B3LYP/ 6-31G* level while freezing the internal coordinates of all of the heavy atoms.

\section{ASSOCIATED CONTENT}

\section{S Supporting Information}

The Supporting Information is available free of charge on the ACS Publications website at DOI: 10.1021/acsomega.7b00900.

PDF file comprising Tables S1-S3, Figure S1, and coordinates of all of the optimized (partially and fully) rotamers of $\mathbf{1}$. Crystal data in the CIF file format for the multiple solvate (CCDC 1535877) and the new DMSO solvate (CCDC 1535878) of 1 (PDF)

\section{AUTHOR INFORMATION}

\section{Corresponding Authors}

*E-mail: felipe@ufg.br (F.T.M.).

*E-mail: adefatima@qui.ufmg.br (A.d.F.).

ORCID

Felipe Terra Martins: 0000-0001-9004-0927

Ariel M. Sarotti: 0000-0002-8151-0306

Ângelo de Fátima: 0000-0003-3010-695X

Notes

The authors declare no competing financial interest.

\section{ACKNOWLEDGMENTS}

This work was funded by the Fundação de Amparo à Pesquisa do Estado de Goiás (FAPEG), Fundação de Amparo à Pesquisa do Estado de Minas Gerais (FAPEMIG), Conselho Nacional de Desenvolvimento Científico e Tecnológico (CNPq), Coordenação de Aperfeiçoamento de Pessoal de Nivel Superior (CAPES). F.T.M. and A.d.F. thank FAPEG and CNPq, respectively, for their research fellowship.

\section{REFERENCES}

(1) (a) Li, Z.-Y.; Chen, Y.; Zheng, C.-Q.; Yin, Y.; Wang, L.; Sun, X.Q. Highly Enantioselective Aldol Reactions Catalyzed by Reusable Upper Rim-Functionalized Calix[4]arene-Based L-Proline Organocatalyst in Aqueous Conditions. Tetrahedron 2017, 73, 78-85. (b) Reinhoudt, D. Rocco Ungaro, 40 Years of Calixarene Chemistry. Supramol. Chem. 2016, 28, 342-350. (c) Kaufmann, L.; Kennedy, S. R.; Jones, C. D.; Steed, J. W. Cavity-Containing Supramolecular Gels as a Crystallization Tool for Hydrophobic Pharmaceuticals. Chem. Commun. 2016, 52, 10113-10116. (d) Sansone, F.; Baldini, L.; Casnati, A.; Ungaro, R. Calixarenes: From Biomimetic Receptors to Multivalent Ligands for Biomolecular Recognition. New J. Chem. 2010, 34, 2715-2728.

(2) (a) Pang, T.-T.; Liu, H.-L.; Du, L.-M.; Chang, Y.-X.; Fu, Y.-L. Supramolecular interaction of two Tryptophans with $p$-Sulfonated calix $[4,6,8]$ arene. J. Fluoresc. 2014, 24, 143-152. (b) Böhmer, V. Calixarenes, Macrocycles with (Almost) Unlimited Possibilities. Angew. Chem., Int. Ed. 1995, 34, 713-745.

(3) (a) An, L.; Han, L.-L.; Zheng, Y.-G.; Peng, X.-N.; Xue, Y.-S.; Gu, X.-K.; Sun, J.; Yan, C.-G. Synthesis, X-Ray Crystal Structure and AntiTumor Activity of Calix[n] arene Polyhydroxyamine Derivatives. Eur. J. Med. Chem. 2016, 123, 21-30. (b) Pur, F. N. Calixdrugs: CalixareneBased Clusters of Established Therapeutic Drug Agents. Mol. Diversity 2016, 20, 781-787. (c) Murphy, P.; Dalgarno, S. J.; Paterson, M. J. Elucidating the Ring Inversion Mechanism(s) for Biscalixarenes. J. Phys. Chem. A 2014, 118, 7986-8001.

(4) (a) Sato, T.; Kawakami, Y.; Tanaka, K.; Suzuno, K.; Takaya, Y.; Kabe, Y. Silanol-modified Calix[4]arene Conformers: Syntheses,
Structures, and Properties. Chem. Lett. 2017, 46, 175-177. (b) Lande, D. N.; Gejji, S. P. Cooperative Hydrogen Bonding, Molecular Electrostatic Potentials, and Spectral Characteristics of Partial Thia-Substituted Calix[4]arene Macrocycles. J. Phys. Chem. A 2016, 120, 7385-7397. (c) Chinta, J. P.; Ramanujam, B.; Rao, C. P. Structural Aspects of the Metal Ion Complexes of the Conjugates of Calix[4]arene: Crystal Structures and Computational Models. Coord. Chem. Rev. 2012, 256, 2762-2794. (D) Joseph, R.; Rao, C. P. Ion and Molecular Recognition by Lower Rim 1,3-Di-conjugates of Calix[4]arene as Receptors. Chem. Rev. 2011, 111, 4658-4702.

(5) (a) Salvio, R.; Volpi, S.; Cacciapaglia, R.; Sansone, F.; Mandolini, L.; Casnati, A. Phosphoryl Transfer Processes Promoted by a Trifunctional Calix[4]arene Inspired by DNA Topoisomerase I. J. Org. Chem. 2016, 81, 9012-9019. (b) de Rosa, M.; Soriente, A.; Concilio, G.; Talotta, C.; Gaeta, C.; Neri, P. Nucleophilic Functionalization of the Calix[6] arene Para- and Meta-Position via p-Bromodienone Route. J. Org. Chem. 2015, 80, 7295-7300. (c) Kennedy, S.; Beavers, C. M.; Teat, S. J.; Dalgarno, S. J. Salt Formation Affects the Conformational and Assembly Properties of pCarboxylatocalix[4] arenes. CrystEngComm 2014, 16, 3712-3717.

(6) Gutsche, C. D.; Dhawan, B.; No, K. H.; Muthukrishnan, R. Calixarenes. 4. The synthesis, Characterization, and Properties of the Calixarenes from p-tert-Butylphenol. J. Am. Chem. Soc. 1981, 103, 3782-3792.

(7) (a) Lande, D. N.; Bhadane, S. A.; Gejji, S. P. Noncovalent Interactions Accompanying Encapsulation of Resorcinol within Azacalix[4]pyridine Macrocycle. J. Phys. Chem. A 2017, 121, 18141824. (b) Murphy, P.; Dalgarno, S. J.; Paterson, M. J. Transition Metal Complexes of Calix[4]arene: Theoretical Investigations into Small Guest Binding within the Host Cavity. J. Phys. Chem. A 2016, 120, 824-839. (c) Morohashi, N.; Nanbu, K.; Tonosaki, A.; Noji, S.; Hattori, T. Comparison of Inclusion Properties between p-tertButylcalix[4]arene and p-tert-Butylthiacalix[4]arene towards Primary Alcohols in Crystals. CrystEngComm 2015, 17, 4799-4808. (d) Murphy, P.; McKinlay, R. G.; Dalgarno, S. J.; Paterson, M. J. Toward Understanding of the Lower Rim Binding Preferences of Calix[4]arene. J. Phys. Chem. A 2015, 119, 5804-5815. (e) Depauw, A.; Kumar, N.; Ha-Thi, M.-H.; Leray, I. Calixarene-Based Fluorescent Sensors for Cesium Cations Containing BODIPY Fluorophore. J. Phys. Chem. A 2015, 119, 6065-6073. (f) Walton, M. J.; Lancaster, S. J.; Wright, J. A.; Elsegood, M. R. J.; Redshaw, C. Zinc Calixarene Complexes for the Ring Opening Polymerization of Cyclic Esters. Dalton Trans. 2014, 43, 18001-18009. (g) Edwards, N. Y.; Liu, F.; Chen, G. Experimental and Computational Studies of Anion Recognition by Pyridine-Functionalised Calixarenes. Supramol. Chem. 2013, 25, 481-489. (h) Saponar, A.; Popovici, E.-J.; Perhaita, I.; Nemes, G.; Cadis, A.-I. Thermal Behaviour of Some Ester Derivatives of p-tert-Butyl Calix[n] arene. J. Therm. Anal. Calorim. 2012, 110, 349356. (i) Udachin, K. A.; Enright, G. D.; Brown, P. O.; Ripmeester, J. A. Pseudopolymorphism in the $p$-tert-Butylcalix[4]arene-N-Butylamine System: Directing the Structural Motifs. Chem. Commun. 2002, 21622163.

(8) Wolfgong, W. J.; Talafuse, L. K.; Smith, J. M.; Adams, M. J.; Adeogba, F.; Valenzuela, M.; Rodriguez, E.; Contreras, K.; Carter, D. M.; Bacchus, A.; McGuffey, A. R.; Bott, S. G. The Influence of Solvent of Crystallization upon the Solid-State Conformation of Calix[6]arenes. Supramol. Chem. 1996, 7, 67-78.

(9) Molins, M. A.; Nieto, P. M.; Sánchez, C.; Prados, P.; de Mendoza, J.; Pons, M. Solution Structure and Conformational Equilibria of a Symmetrical Calix[6] arene. Complete Sequential and Cyclostereospecific Assignment of the Low-Temperature NMR Spectra of a Cycloasymmetric Molecule. J. Org. Chem. 1992, 57, 6924-6931.

(10) Janssen, R. G.; van Duynhoven, J. P. M.; Verboom, W.; van Hummel, G. J.; Harkema, S.; Reinhoudt, D. N. Studies on the Dynamics of Phosphorylated $p$-tert-Butylcalix[6]arenes by Using $2 \mathrm{D}$ NMR Spectroscopy. J. Am. Chem. Soc. 1996, 118, 3666-3675.

(11) (a) Ramon, G.; Jacobs, A.; Nassimbeni, L. R.; Yav-Kabwit, R. Inclusion Compounds of $p$-tert-Butylcalixarenes: Structures, Kinetics, and Selectivity. Cryst. Growth Des. 2011, 11, 3172-3182. (b) Felsmann, 
M.; Schwarzer, A.; Weber, E. 5,11,17,23,29,35-Hexa-tert-butyl37,38,39,40,41,42-hexahydroxycalix[6] arene Dichloromethane Disolvate. Acta Crystallogr., Sect. E: Struct. Rep. Online 2006, 62, o607-o609. (c) Makha, M.; Raston, C. L.; Sobolev, A. N.; Turner, P. Exclusive Endo-Cavity Interplay of $t$-Bu-calix[6] arene with $\mathrm{C}_{70}$. Cryst. Growth Des. 2006, 6, 224-228. (d) Dale, S. H.; Elsegood, M. R. J.; Redshaw, C. Polymorphism and Pseudopolymorphism in Calixarenes: Acetonitrile Clathrates of $p$-But-Calix $[n]$ arenes $(n=6$ and 8). CrystEngComm 2003, 5, 368-373. (e) Schatz, J.; Schildbach, F.; Lentz, A.; Rastatter, S.; Schilling, J.; Dormann, J.; Ruoff, A.; Debaerdemaeker, T. The Inclusion of Carbon Disulfide in p-tert-Butylcalix[4]- and [6] arene - A Combined Crystallographic and Vibrational Spectroscopic Study. Z. Naturforsch Sect. B 2000, 55, 213-221. (f) Lu, T. B.; Li, X. Y.; Ji, L. N.; Han, B. H.; Liu, Y.; Yu, K. B. Crystal and Molecular Structure of an Inclusion Complex of p-tert-Butylcalix[6] arene with Toluene. Chem. Res. Chin. Univ. 1999, 15, 1-4. (g) Thuéry, P.; Keller, N.; Lance, M.; Vigner, J. D.; Nierlich, M. An Inclusion Complex between Acetonitrile and p-tert-Butylcalix[6]arene. J. Inclusion Phenom. Mol. Recognit. Chem. 1994, 20, 373-379. (h) Xu, W.; Puddephatt, R. J.; Manojlovic-Muir, L.; Muir, K. W.; Frampton, C. S. Calixarenes: Structure of an Acetonitrile Inclusion Complex and Some Transition Metal Rimmed Derivatives. J. Inclusion Phenom. Mol. Recognit. Chem. 1994, 19, 277290. (i) Andreetti, G. D.; Ugozzoli, F.; Casnati, A.; Ghidine, E.; Pochini, A.; Ungaro, R. Molecular Inclusion in Functional Macrocycles. 17. Crystal and Molecular-Structure of $p$-tert-Butylcalix[6]arene 1-1 Tetrachloroethylene Clathrate. Gazz. Chim. Ital. 1989, 119, 4750. (j) Halit, M.; Oehler, D.; Perrin, M.; Thozet, A.; Perrin, R.; Vicens, J.; Bourakhouadar, M. Crystal and Molecular Structure of two Calix[6]arenes:p-Isopropylcalix[6] arene and p-tert-Butylcalix[6]arene-Benzene (1:3) Complex. J. Inclusion Phenom. 1988, 6, 613623.

(12) Arbaoui, A.; Redshaw, C.; Elsegood, M. R. J.; Wright, V. E.; Yoshizawa, A.; Yamato, T. Iron(III) and Zinc(II) Calixarene Complexes: Synthesis, Structural Studies, and Use as Procatalysts for $\varepsilon$-Caprolactone Polymerization. Chem. Asian J. 2010, 5, 621-633.

(13) Kim, K.; Choe, J.-I. DFT Conformational Study of Calix[6]arene: Hydrogen Bond. Bull. Korean Chem. Soc. 2009, 30, 837-845.

(14) (a) Zhou, F.; Liu, R.; Li, P.; Zhang, H. On the Properties of S... $\mathrm{O}$ and $S \cdots \Pi$ Noncovalent Interactions: The Analysis of Geometry, Interaction Energy and Electron Density. New J. Chem. 2015, 39, 1611-1618. (b) Wan, C.-Q.; Han, J.; Mak, T. C. W. Intermolecular S... Interactions in Crystalline Sulfanyl-Triazine Derivatives. New J. Chem. 2009, 33, 707-712.

(15) (a) Singh, S. K.; Das, A. The $\mathrm{N} \rightarrow \Pi^{*}$ Interaction: A Rapidly Emerging Non-Covalent Interaction. Phys. Chem. Chem. Phys. 2015, 17, 9596-9612. (b) Ringer, A. L.; Senenko, A.; Sherrill, C. D. Models of $\mathrm{S} / \pi$ Interactions in Protein Structures: Comparison of the $\mathrm{H}_{2} \mathrm{~S}-$ Benzene Complex with PDB Data. Protein Sci. 2007, 16, 2216-2223.

(16) Thomas, R.; Shoemaker, C. B.; Eriks, K. The Molecular and Crystal Structure of Dimethyl Sulfoxide, $\left(\mathrm{H}_{3} \mathrm{C}\right)_{2} \mathrm{SO}$. Acta Crystallogr. 1966, 21, 12-20.

(17) Hanna, T. A.; Liu, L.; Angeles-Boza, A. M.; Kou, X.; Gutsche, C. D.; Ejsmont, K.; Watson, W. H.; Zakharov, L. N.; Incarvito, C. D.; Rheingold, A. L. Synthesis, Structures, and Conformational Characteristics of Calixarene Monoanions and Dianions. J. Am. Chem. Soc. 2003, 125, 6228-6238.

(18) SADABS, APEX2 and SAINT; Bruker AXS Inc.: Madison, WI, 2009.

(19) Burla, M. C.; Caliandro, R.; Camalli, M.; Carrozzini, B.; Cascarano, G. L.; De Caro, L.; Giacovazzo, C.; Polidori, G.; Spagna, R. SIR2004: An Improved Tool for Crystal Structure Determination and Refinement. J. Appl. Crystallogr. 2005, 38, 381-388.

(20) Sheldrick, G. M. A Short History of SHELX. Acta Crystallogr., Sect. A: Found. Crystallogr. 2008, 64, 112-122.

(21) Macrae, C. F.; Bruno, I. J.; Chisholm, J. A.; Edgington, P. R.; Mccabe, P.; Pidcock, E.; Monge, L. R.; Taylor, R.; van de Streek, J.; Wood, P. A. Mercury CSD 2.0 - New Features for the Visualization and Investigation of Crystal Structures. J. Appl. Crystallogr. 2008, 41, $466-470$.
(22) Farrugia, L. J. WinGX and ORTEP for Windows: An Update. J. Appl. Crystallogr. 2012, 45, 849-854.

(23) (a) Spek, A. L. Single-Crystal Structure Validation with the Program PLATON. J. Appl. Crystallogr. 2003, 36, 7-13. (b) Spek, A. L. PLATON SQUEEZE: A Tool for the Calculation of the Disordered Solvent Contribution to the Calculated Structure Factors. Acta Crystallogr., Sect. C: Struct. Chem. 2015, 71, 9-18.

(24) Frisch, M. J.; Trucks, G. W.; Schlegel, H. B.; Scuseria, G. E.; Robb, M. A.; Cheeseman, J. R.; Scalmani, G.; Barone, V.; Mennucci, B.; Petersson, G. A.; Nakatsuji, H.; Caricato, M.; Li, X.; Hratchian, H. P.; Izmaylov, A. F.; Bloino, J.; Zheng, G.; Sonnenberg, J. L.; Hada, M.; Ehara, M.; Toyota, K.; Fukuda, R.; Hasegawa, J.; Ishida, M.; Nakajima, T.; Honda, Y.; Kitao, O.; Nakai, H.; Vreven, T.; Montgomery, J. A., Jr.; Peralta, J. E.; Ogliaro, F.; Bearpark, M.; Heyd, J. J.; Brothers, E.; Kudin, K. N.; Staroverov, V. N.; Kobayashi, R.; Normand, J.; Raghavachari, K.; Rendell, A.; Burant, J. C.; Iyengar, S. S.; Tomasi, J.; Cossi, M.; Rega, N.; Millam, J. M.; Klene, M.; Knox, J. E.; Cross, J. B.; Bakken, V.; Adamo, C.; Jaramillo, J.; Gomperts, R.; Stratmann, R. E.; Yazyev, O.; Austin, A. J.; Cammi, R.; Pomelli, C.; Ochterski, J. W.; Martin, R. L.; Morokuma, K.; Zakrzewski, V. G.; Voth, G. A.; Salvador, P.; Dannenberg, J. J.; Dapprich, S.; Daniels, A. D.; Farkas, O.; Foresman, J. B.; Ortiz, J. V.; Cioslowski, J.; Fox, D. J. Gaussian 09; Gaussian Inc.: Wallingford, CT, 2009.

(25) (a) Lee, C.; Yang, W.; Parr, R. G. Development of the ColleSalvetti Correlation-Energy Formula into a Functional of The Electron Density. Phys. Rev. B 1988, 37, 785-789. (b) Becke, A. D. A New Mixing of Hartree-Fock and Local Density-Functional Theories. J. Chem. Phys. 1993, 98, 1372-1377. (c) Becke, A. D. Density functional thermochemistry. III. The role of exact exchange. J. Chem. Phys. 1993, $98,5648-5652$. 